This item was submitted to Loughborough's Research Repository by the author.

Items in Figshare are protected by copyright, with all rights reserved, unless otherwise indicated.

\title{
Effects of environmental changes in a stair climbing intervention:
} generalization to stair descent

\section{PLEASE CITE THE PUBLISHED VERSION}

http://healthpromotionjournal.com/mm5/merchant.mvc?

Screen=PROD\&Store_Code=AJHP\&Product_Code=JV22I138\&Category_Code=

\section{PUBLISHER}

(c) American Journal of Health Promotion, inc.

\section{VERSION}

AM (Accepted Manuscript)

\section{LICENCE}

CC BY-NC-ND 4.0

\section{REPOSITORY RECORD}

Webb, Oliver J., and Frank F. Eves. 2019. "Effects of Environmental Changes in a Stair Climbing Intervention: Generalization to Stair Descent”. figshare. https://hdl.handle.net/2134/8925. 
This item was submitted to Loughborough's Institutional Repository (https://dspace.lboro.ac.uk/) by the author and is made available under the following Creative Commons Licence conditions.

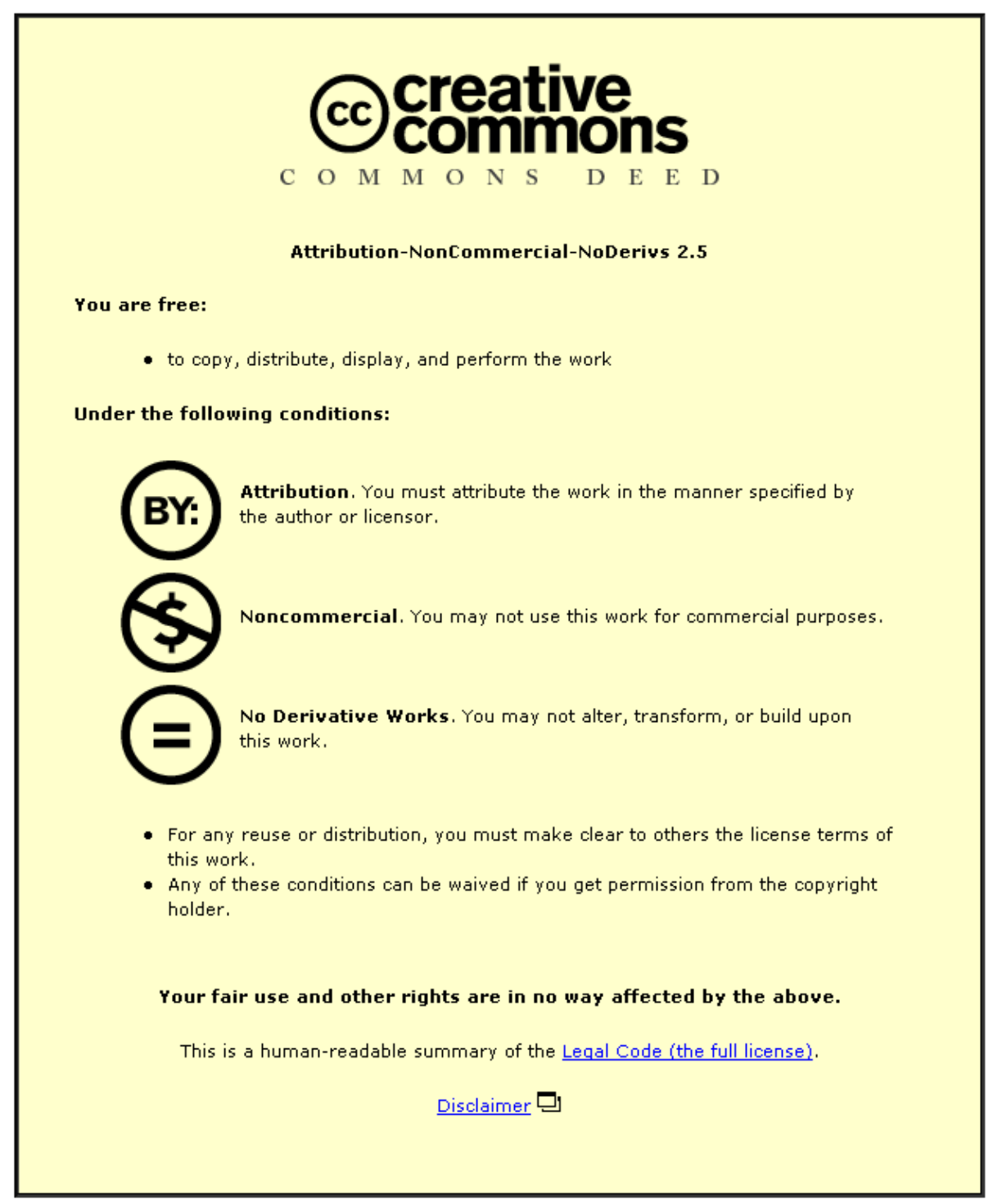

For the full text of this licence, please go to: http://creativecommons.org/licenses/by-nc-nd/2.5/ 
Effects of Environmental Changes in a Stair Climbing Intervention: Generalization to Stair Descent

American Journal of Health Promotion, 2007; 22: 38-44

Oliver J. Webb, Frank F. Eves 


\begin{abstract}
Purpose

Visual improvements have been shown to encourage stair use in worksites, independent of written prompts. This study examined whether visual modifications alone can influence behavior in a shopping mall. Climbing one flight of stairs, however, will not confer health benefits.

Therefore, this study also assessed whether exposure to the intervention encouraged subsequent stair use.

Design

Interrupted time-series design.

Settings

Escalators flanked by a staircase on either side.

Subjects
\end{abstract}

Ascending and descending pedestrians $(N=81,948)$

Interventions

Following baseline monitoring, a colorful design was introduced on the stair-risers of one staircase (the 'target' staircase). A health promotion message was later superimposed on top. The intervention was only visible to ascending pedestrians. Thus, any rise in descending stair use would indicate increased intention to use stairs, which endured after initial exposure to the intervention.

Measures

Observers inconspicuously coded pedestrians' means of ascent/descent and demographic characteristics. 


\section{Results}

The design alone had no meaningful impact. Addition of the message, however, increased stair climbing at the target and non-target staircases by $190 \%$ and 52\%, respectively. The message also produced a modest increase in stair descent at the target (25\%) and non-target staircases (9\%).

\section{Conclusions}

In public venues a message component is critical to the success of interventions. In addition, it appears that exposure to an intervention can encourage pedestrians to use stairs on a subsequent occasion. 


\section{Purpose}

Physical activity reduces the risk of type-2 diabetes, stroke, cardiovascular diseases and certain cancers. ${ }^{1,2}$ Despite these protective effects, around $70 \%$ of people in developed countries remain insufficiently active. ${ }^{3,4}$ Guidelines from the 1990s, which promoted vigorous exercise, proved overambitious and failed to significantly raise population activity levels. ${ }^{5}$ In light of these difficulties present recommendations are broader in scope, encouraging at least 30 minutes of moderate activity per day, which may be accumulated in 10 minute bouts. ${ }^{2}$

Health agencies in North America ${ }^{6,7}$ and the U.K. ${ }^{4}$ acknowledge stair climbing as a useful means of accruing physical activity. Opportunities to climb stairs are abundant and viable for most populations groups. Many traditional barriers to exercise, such as equipment costs and inclement weather, do not apply. Yet whilst stair climbing is an incidental feature of everyday life it represents a physiologically vigorous activity, expending 8.6-9.6 times the energy used at rest. ${ }^{8,9}$ Stair use has thus been associated with key health benefits, including enhanced cardiorespiratory fitness and improved blood lipid profiles. ${ }^{10,11}$

In public-access settings pedestrians predominantly use escalators, with an average of only $5.5 \%$ taking the stairs. ${ }^{12}$ Where a behavior is frequently performed it is likely to become a firmly entrenched habit. ${ }^{14,17}$ Therefore, it is doubtful that each time an individual mounts an escalator they make a deliberate decision to do so. ${ }^{13}$ Rather, using escalators instead of the stairs becomes a habit. According to current theory, habitual behaviors can become associated with the context in 
which they are usually performed. ${ }^{14-18}$ As such, the presentation of environmental cues can elicit behavior relatively automatically, without need for conscious deliberation. Thus, when confronted with the familiar sight of adjacent stairs and escalators, individuals 'mindlessly' proceed up the escalator. ${ }^{13}$ Several studies show, however, that it is possible to manipulate stair/escalator choices in the field. Typically, a poster is installed at the 'point-of-choice' between stairs and escalators, emphasising the benefits of stair climbing. These interventions increased stair climbing relative to baseline by a median value of $68 \%($ range $=20 \%-166 \%) .{ }^{19-26}$ In an alternative approach, message banners were attached to the stair-risers themselves, producing even greater increases in stair climbing $($ median $=146 \%$; range $=127 \%-179 \%) .{ }^{13,27-29}$

Previous research indicates that stair-riser banners outperform posters because they are more visible and hence more effective in disseminating information; in earlier studies $37 \%$ of people reported seeing posters whereas $78 \%$ recalled banners. ${ }^{23,27,29}$ It is possible, however, that banners influence stair use by virtue of visibility alone, regardless of any written content. In two worksite studies, for example, aesthetic improvements such as redecorating and installing artwork were found to increase stair usage independent of the effects of message prompts. ${ }^{30,31}$ The banners used in previous studies consisted of expansive areas of bright primary color which, in accordance with current theory, may have disrupted the predictable visual context associated with escalator use, so producing an increase in stair climbing. ${ }^{17}$ Therefore, the first aim of this study was to establish whether visual modifications alone can influence stair usage in a public-access site. 
Climbing a single set of stairs, however, will not confer meaningful health benefits. The objective must be to encourage individuals to accumulate stair use. For instance, it is estimated that seven minutes of stair climbing per day would expend the equivalent energy required to reduce the ten-

year risk of coronary death by $62 \% .^{32}$ Thus, it is important to establish whether the effects of stair climbing interventions 'generalize' beyond the intervention setting. That is, does exposure to a point-of-choice prompt also encourage pedestrians to use stairs when they encounter a subsequent opportunity to do so? To examine this question we assessed if the current intervention continued to influence behaviour once it was no longer visible. The study setting featured both ascending and descending escalators, flanked by staircases. The site therefore catered for pedestrians travelling in both directions. The intervention was only visible to ascending pedestrians. Hence, monitoring of descending traffic provided a means of assessing generalization. Any rise in descending stair use would indicate an increased intention to use stairs which outlasted exposure to the intervention. These findings have important implications for the viability of promoting stair use as a means of increasing population activity levels.

\section{Methods}

Design

A quasi-experimental interrupted time-series design was adopted. Baseline stair use was monitored at a single point-of-choice location in a UK shopping precinct. A six-week intervention period then followed. Figure 4.1 provides an aerial view of the experimental site, which lay along a kinked corridor. 
Figure 4.1: An aerial perspective of the experimental site

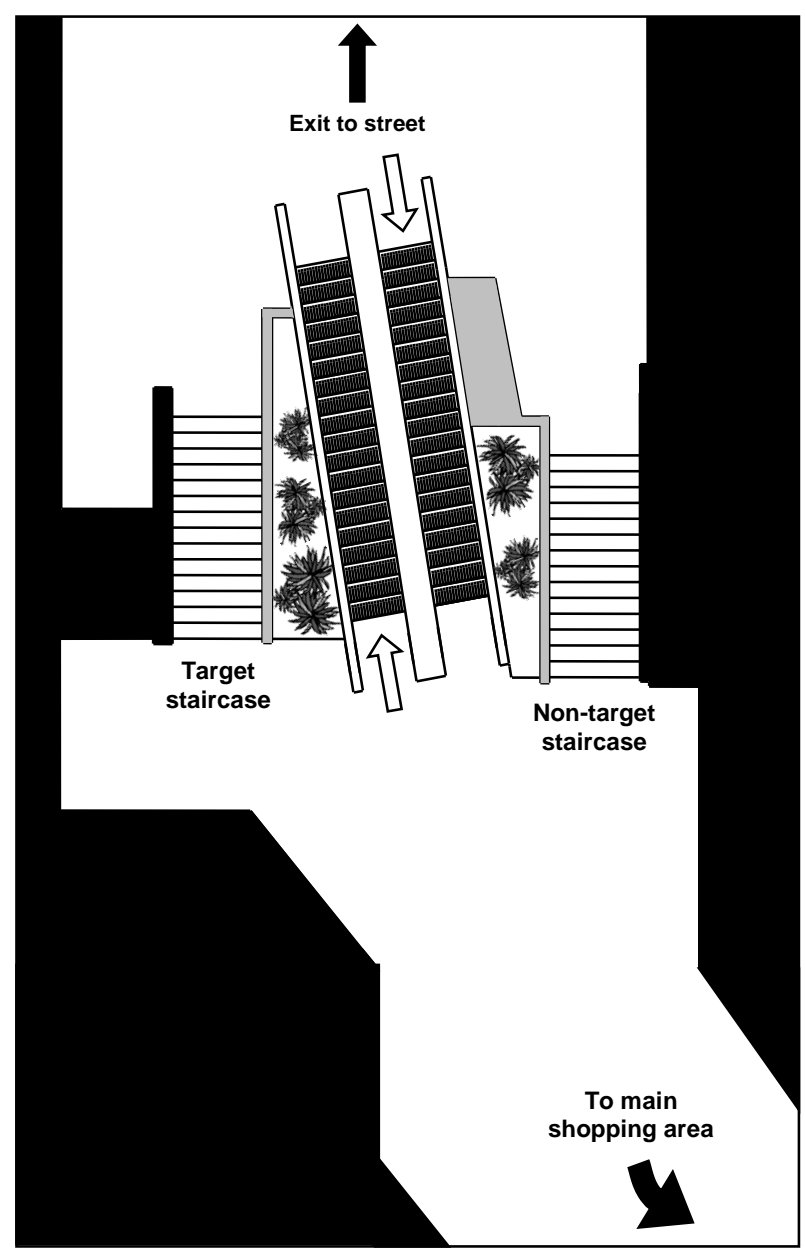

A central bank of escalators was flanked by 15 -step staircases. Each staircase was separated from the escalators by a waist-high wall of patterned-glass and foliage. As Figure 4.1 shows, pedestrians approaching the site from the shopping area would reach the 'non-target' staircase before the 'target' staircase. Indeed, the non-target staircase provided the shortest route for pedestrians travelling in either direction. 


\section{Sample}

Over the course of the study a total of 42,313 ascending pedestrians and 39,635 descending pedestrians were observed. In addition, a convenience sample of 271 pedestrians were interviewed to assess their recall of the intervention.

\section{Measures}

From a pool of four alternating personnel (inter-observer agreement=97\%) one observer monitored ascending pedestrians whilst a colleague simultaneously monitored descending pedestrians. Observers logged whether individuals rode the escalator or, in the case of stair users, which of the two staircases they chose. Gender, age, ethnicity and baggage were also coded using a protocol employed in previous research. ${ }^{13}$ Observations were made twice weekly, between $12.30 \mathrm{pm}$ and $4 \mathrm{pm}$, to include lunch and daytime users.

During the final week a convenience sample of ascending pedestrians were interviewed at the top of the stairs/escalator. Of 187 escalator users and 218 stair users (target staircase $=115$; non-target staircase=103) approached, 100 and 171 (target staircase=100; non-target staircase=71), respectively, agreed to participate. Respondents were asked whether they recalled the text on the stairs. One point was available for recalling the "Take the stairs" prompt and another point for recalling the "7 minutes..." message. Points were awarded for perfect responses and those which were semantically correct. 


\section{Intervention}

Baseline monitoring was followed by a three-week 'design alone' phase, which involved the installation of a colorful design on the stair-risers of the target staircase alone. By only modifying one of the staircases we tested whether the intervention increased overall stair use or merely altered the distribution of stair usage between staircases. A final three-week 'design plus message' phase followed, in which the prompt "Take the stairs" and the message "7 minutes of stair climbing daily protects your heart" were superimposed over the design (see Figure 4.2). The intervention was highly visible to pedestrians ascending the target staircase or adjacent upward escalator. By contrast, for pedestrians approaching the non-target staircase the intervention was partially obscured due to the recessed position of the target staircase and the intervening glass walls and foliage.

Analysis

Ascending and descending data were analysed separately using logistic regression, with stair/escalator choice serving as the dichotomous outcome variable. Gender, age, ethnicity, baggage and pedestrian traffic volume were also entered into all models, having previously been

shown to have important effects. ${ }^{14,20-23,25-28,30}$ In addition, respective percentage recall rates were calculated for the prompt and the message. 
Figure 4.2: The 'target' staircase during the design plus message phase

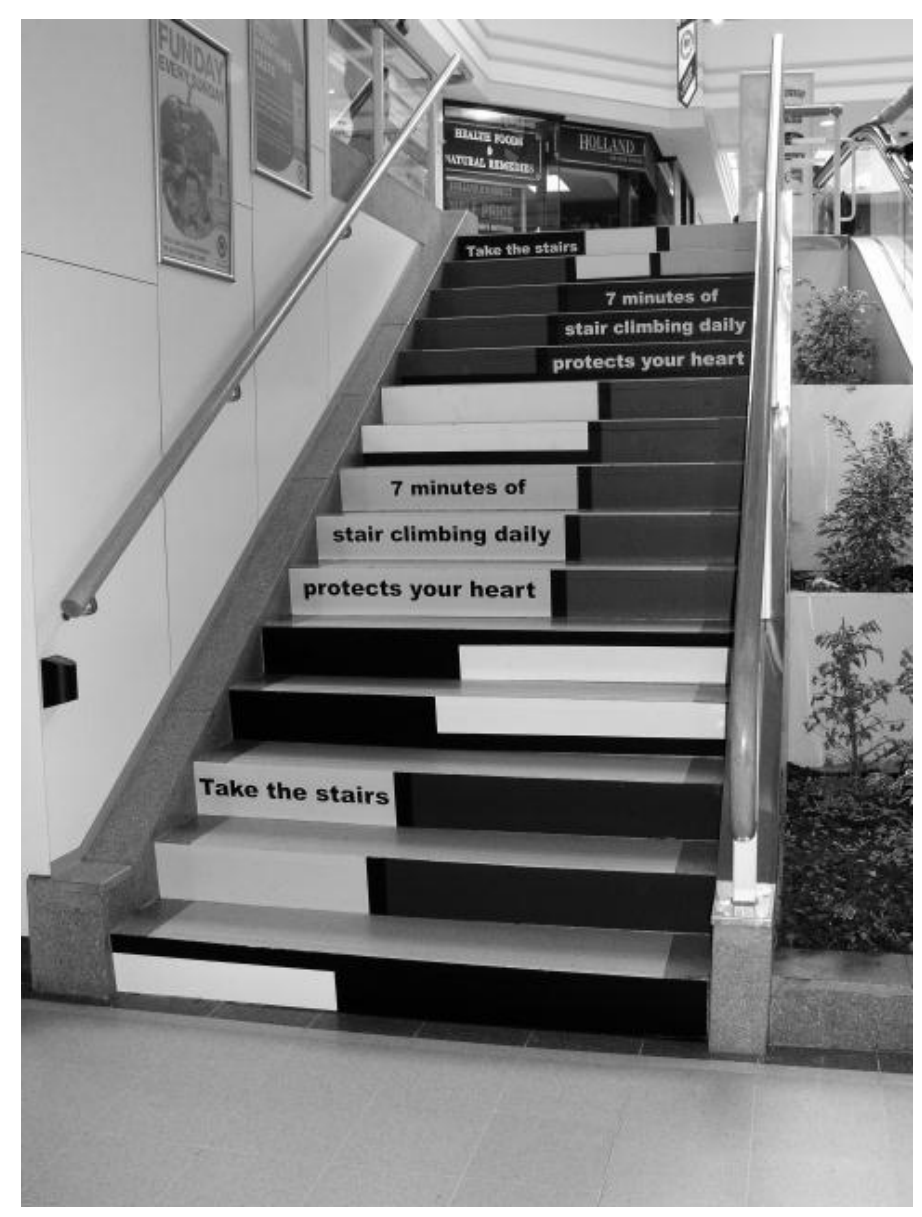

\section{Results}

\section{Ascending Traffic}

Of the 42,313 pedestrians observed $55.6 \%$ were female, $76.0 \%$ were White and $93.4 \%$ were classified as under 60 years old. Throughout the study main effects were observed at both staircases, such that men (target staircase: odds ratio $[\mathrm{OR}]=1.24,95 \%$ confidence interval $[C I]=1.14,1.36$; non-target staircase: $\mathrm{OR}=1.63, \mathrm{CI}=1.49,1.77$ ), White persons (target staircase: $\mathrm{OR}=2.25, \mathrm{CI}=1.99,2.55$; non-target staircase: $\mathrm{OR}=2.26, \mathrm{CI}=2.00,2.55$ ), people aged under 60 
(target staircase: $\mathrm{OR}=2.54, \mathrm{CI}=1.99,3.24$; non-target staircase: $\mathrm{OR}=1.61, \mathrm{CI}=1.32,1.96$ ) and those without large bags (target staircase: $\mathrm{OR}=1.69, \mathrm{CI}=1.38,2.07$; non-target staircase: $\mathrm{OR}=1.49, \mathrm{CI}=1.22,1.81)$ climbed the stairs more than their counterparts. Significant effects of pedestrian traffic volume were also observed at both staircases $(p<.001)$, with more people climbing the stairs during busier periods.

Figure 4.3 depicts stair ascent over the course of the study. As can be seen, baseline stair use was higher at the non-target staircase than at the target staircase. There was no significant change in stair climbing between baseline and the introduction of the design alone, either at the target $(\mathrm{OR}=0.88, \mathrm{CI}=0.77,1.01)$ or non-target staircase $(\mathrm{OR}=0.97, \mathrm{CI}=0.87,1.09)$. Data from the baseline and design alone phase were therefore collapsed and compared to the design plus message phase. Addition of the message increased stair climbing at both the target $(\mathrm{OR}=2.90$, $\mathrm{CI}=2.55,3.29)$ and non-target staircases $(\mathrm{OR}=1.52, \mathrm{CI}=1.34,1.74)$. Close inspection of Figure 4.3 suggests that this increase was more pronounced amongst females than males. This impression was confirmed in analyses. At both staircases there was a significant interaction between gender and the design plus message phase, meaning that the ORs for women (target staircase: $\mathrm{OR}=2.99, \mathrm{CI}=2.62,3.41$; non-target staircase: $\mathrm{OR}=1.56, \mathrm{CI}=1.37,1.79$ ) were greater than for men (target staircase: $\mathrm{OR}=2.06, \mathrm{CI}=1.80,2.35$; non-target staircase: $\mathrm{OR}=1.14, \mathrm{CI}=1.00$, 1.29). In order to assess the durability of effects, successive weeks of the design plus message phase were compared. These analyses revealed no significant decline in stair use at either staircase. 
Figure 4.3. Ascending stair use at the target and non-target staircase, stratified by gender.

Target Staircase

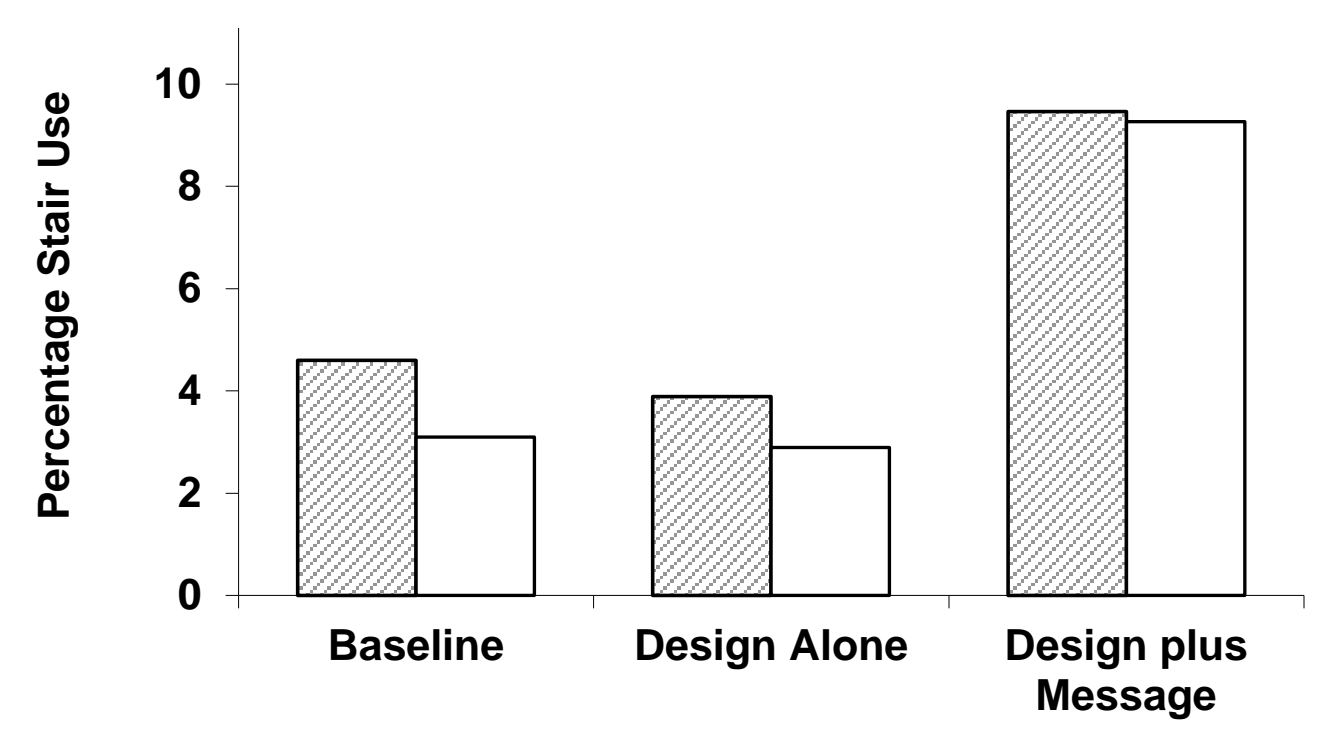

Non-Target Staircase

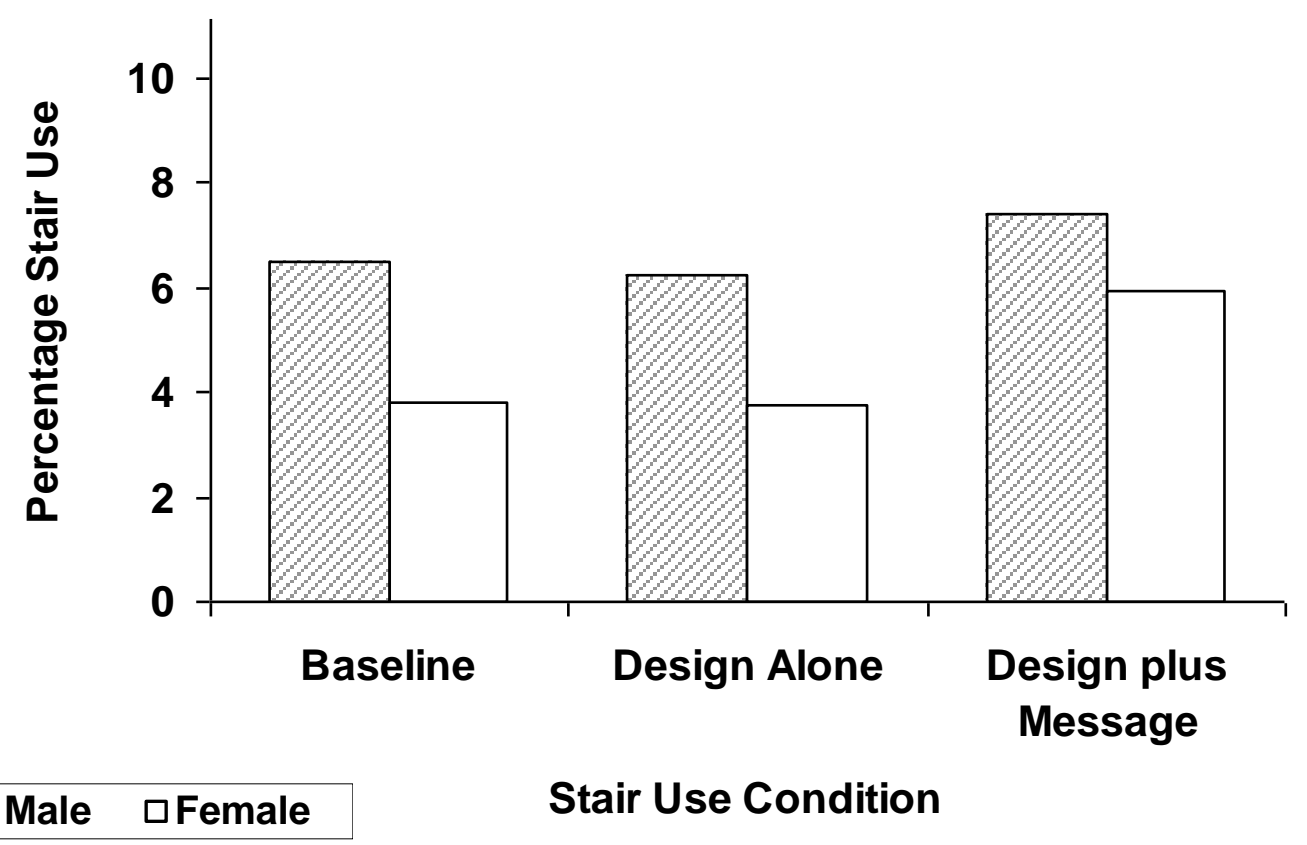




\section{Descending Traffic}

Of the 39,635 pedestrians observed $55.4 \%$ were female, $71.3 \%$ were White and $92.1 \%$ were coded as under 60 years old. Throughout the study demographic effects were observed on both staircases, such that males (target staircase: $\mathrm{OR}=1.44, \mathrm{CI}=1.27,1.62$; non-target staircase: $\mathrm{OR}=1.33, \mathrm{CI}=1.25,1.42$ ), White persons (target staircase: $\mathrm{OR}=1.67, \mathrm{CI}=1.44,1.93$; non-target staircase: $\mathrm{OR}=2.18, \mathrm{CI}=2.01,2.38)$ and those aged under 60 (target staircase: $\mathrm{OR}=2.43, \mathrm{CI}=1.79$, 3.30; non-target staircase: $\mathrm{OR}=1.45, \mathrm{CI}=1.27,1.65)$ descended the stairs more than their counterparts. At the target staircase there was no effect of baggage and only intermittent effects of pedestrian traffic volume. At the non-target staircase significant effects of baggage and pedestrian traffic were observed, with more stair descent amongst unencumbered people (target staircase: $\mathrm{OR}=2.43, \mathrm{CI}=1.79,3.30$; non-target staircase: $\mathrm{OR}=1.45, \mathrm{CI}=1.27,1.65)$ and during busier periods $(p<.01)$. In contrast to the ascending data, there were no significant interactions between demographic characteristics and either intervention phase.

Figure 4.4 illustrates descending stair use throughout the study. Consistent with the results for stair ascent, the baseline rate of descending stair use was higher at the non-target staircase than at the target staircase. During the design alone phase there was a significant increase in stair descent at the target staircase $(\mathrm{OR}=1.35, \mathrm{CI}=1.15,1.60)$. Given that the design alone had no impact on stair ascent, this appears to be a random effect. Importantly, when the message was added a further significant increase in stair descent was observed at the target staircase $(O R=1.25$, $\mathrm{CI}=1.08,1.45$ ). For the non-target staircase effects were straightforward. Consistent with the ascending data, there was no significant change in stair descent between baseline and the design alone phase $(\mathrm{OR}=1.00, \mathrm{CI}=0.92,1.09)$. The data for baseline and the design alone phase were 
therefore collapsed and compared with the design plus message phase. Following addition of the message there was a significant increase in stair descent $(\mathrm{OR}=1.09, \mathrm{CI}=1.02,1.17)$. Week-byweek analyses of the design plus message phase showed no decline in descending stair use at either staircase. 
Figure 4.4. Descending stair use at the target and non-target staircase.

Target Staircase

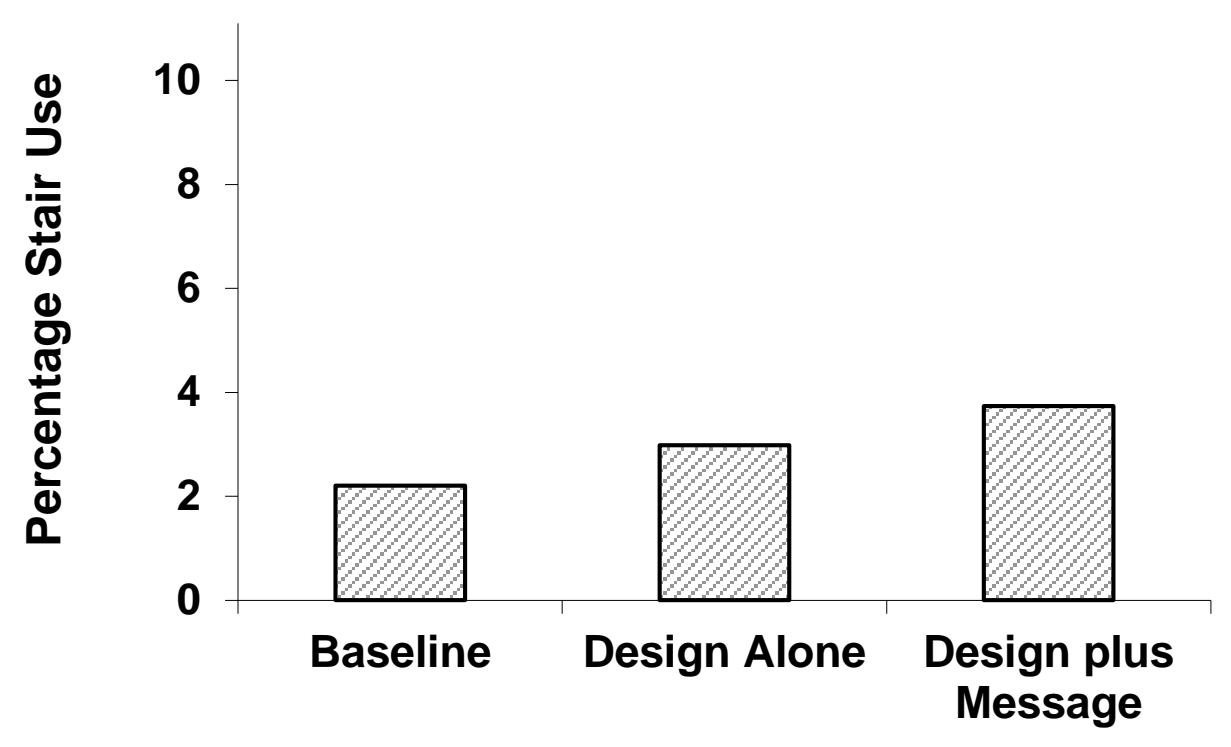

Stair Use Condition
Non-Target Staircase

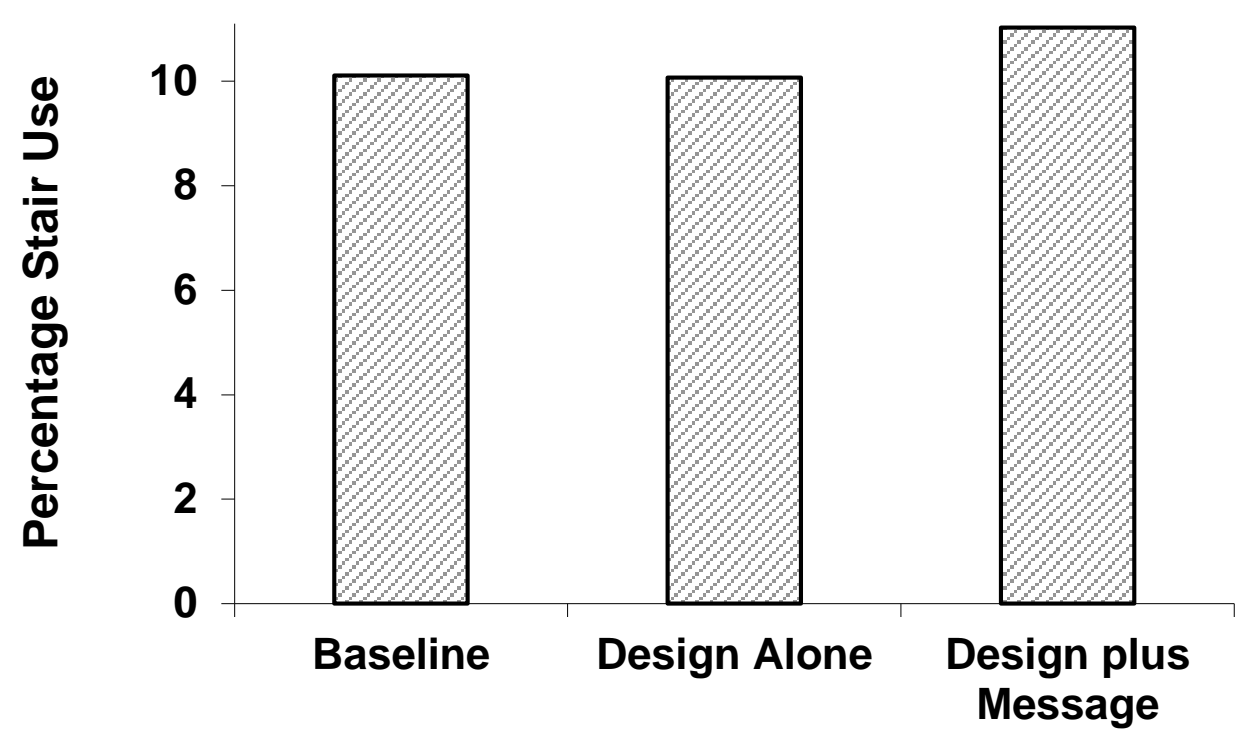

Stair Use Condition 


\section{Interview Data}

The recall rate for the "Take the stairs" prompt amongst respondents from the escalator, target staircase and non-target staircase $(24.0 \%, 41.0 \%$ and $14.1 \%$, respectively) was lower than for the “7 minutes..." message $(47.0 \%, 90.0 \%$ and $31.0 \%$, respectively).

\section{Discussion}

During the design alone phase there was no change in ascending stair use. Following addition of the message, however, a substantial increase in stair climbing was observed. This effect occurred at both staircases, confirming that the intervention increased overall stair climbing, as opposed to merely altering the distribution of pedestrians between the staircases. It appears, therefore, that stair-riser banners do not influence behavior due to visibility alone. Rather, a message component is critical to the success of interventions in public-access settings.

The increase in stair climbing at the target staircase exceeds all previously reported effects. Thus, our results corroborate the superiority of the banner format over conventional posters and support recent research into the optimum intervention design. We used a single message, consistent with Webb and Eves' conclusion that this can be as successful as using multiple different messages. ${ }^{29}$ The current message also emphasised specific health consequences of stair climbing, as this approach may be more effective than providing general descriptions of stair use as in previous interventions (e.g., "free exercise"”, "easy exercise”). ${ }^{33}$ Furthermore, although the "7 minutes..." message has previously been trialed in a worksite intervention, ${ }^{34}$ this was the first study in a public-access setting to convey a specific time goal for the accumulation of stair 
climbing. As the ultimate objective is to encourage accumulation of stair use, the positive reception towards this novel type of message is promising. It is also encouraging that the greatest increase in stair climbing was amongst women. Females are reported to be more sedentary than males, so engaging them in physical activity is a public health priority. ${ }^{2-4}$ Furthermore, certain outcomes of regular stair climbing, such as improved leg extensor strength and reduced risk of osteoporosis, are particularly beneficial to women. ${ }^{35,36}$

It is important to consider why changing the visual environment has previously been shown to influence behavior in worksites but failed to encourage stair climbing here, in a public-access setting. A key contextual difference between the venues may explain this discrepancy. In worksites the choice is typically between an elevator or a stairwell, which may not be adjacent to

each other. ${ }^{12}$ Individuals in worksite studies may have been lured away from the elevator and into the stairwell out of a 'sense of curiosity' at the visual alterations within. ${ }^{31}$ By contrast, in publicaccess settings the choice is usually between adjacent stairs or escalators. Any environmental alterations are visible from either mode of travel. As such, pedestrians in the current study could peruse the design without deviating from their customary choice of the escalator.

During the design alone phase there was an increase in descending stair use at the target staircase. The explanation for this effect is unclear. Given, however, that during the same period there was no change in behavior amongst ascending pedestrians, who could see the design, it is doubtful that the intervention was responsible. Crucially, the introduction of the message produced a further increase in stair descent at both sites. We propose that this increase in stair descent results from pedestrians' previous exposure to the message when travelling in the ascending direction. 
Hence, these findings provide the first evidence that the effects of an intervention on pedestrian behavior 'generalize' to successive stair/escalator scenarios.

Week-by-week analyses confirmed that the increases in stair ascent and stair descent remained robust over the three week lifespan of the design plus message phase. Further research is required to fully ascertain the durability of effects and to establish if any additional benefit can be derived from refreshing the message. Findings from a previous mall-based study are, however, encouraging. In the longest stair-climbing intervention yet staged Kerr et al. compared results from the first six weeks with those in the second six weeks. ${ }^{13}$ Effects remained undiminished in all groups except young women, whilst stair climbing amongst the over 60s actually increased further in the second half of the intervention.

It is important to consider how the message influenced descending stair use when it was no longer visible. Given that escalator use is likely to be a firmly-held habit it is doubtful that three weeks exposure to the message reversed individuals' tendencies, such that they developed a new habit of stair use. ${ }^{13,14,17}$ A more feasible explanation is that individuals assimilated the message content during an earlier ascent of the stairs/escalator and, on returning to the intervention setting, this information provoked a conscious decision to use the stairs.

The different pattern of findings between the respective staircases merits comment. At baseline, both ascending and descending stair use was greater at the non-target staircase compared to the target staircase. The position of the intervention site, along a kinked corridor, can explain this discrepancy. The non-target staircase lay closest to the apex, thus providing the shortest path for 
people travelling in either direction. On level ground individuals minimise walking distance by selecting the shortest route between destinations. ${ }^{37,38}$ Hence, the pattern of stair use at baseline reflects distance minimization by pedestrians.

There were also differential effects of the intervention at each staircase. The increase in stair climbing at the non-target staircase (52\%) was considerably lower than at the target staircase (190\%). Two factors may explain this difference. First, the high level of baseline stair climbing at the non-target staircase could have served to attenuate any statistical effects of the intervention itself. Second, the interview data appears to confirm the earlier caveat that the visibility of the intervention was restricted for people approaching the non-target staircase. The message recall rate at the non-target staircase was much lower than at the target staircase (prompt: $41.0 \%$ vs. 14.1\%; message: $90.0 \%$ vs. $31.0 \%$ ). Thus, the lower intervention response could have resulted from obscured visibility of the message.

Some caution should be exercised in interpreting the current findings. This was the first intervention in a public-access site to consider downward stair/escalator use. Although stair descent can have intrinsic health benefits, ${ }^{9,39}$ the associated energy cost is only around one third of that incurred during ascent (see ${ }^{12}$ ). Hence, from a public health perspective the target outcome remains stair climbing. Whilst our findings indicate that point-of-choice prompts may influence subsequent stair/escalator choices, it is important to replicate these findings in terms of stair ascent. Thus, we conducted a companion study which assessed the effects of a single intervention on stair climbing at multiple stair/escalator pairings within the same venue (Webb and Eves, unpublished data). 
The potential public health impact of generalization effects will only become clear with further research. Verplanken et al., for instance, also succeeded in disrupting individuals' habitual travel choices but found that effects deteriorated over time. ${ }^{40}$ In the current study pedestrians' movements between their initial exposure to the message and subsequent descent of the stairs are unknown. Therefore, it is important to determine if generalization effects diminish as a function of the time or distance travelled from the intervention. Two papers have also noted distinct patterns of stair use in different types of venue. ${ }^{12,24}$ Thus, it is vital to establish if generalization effects diffuse between different settings. Can a mall-based intervention like ours, for instance, influence individuals' behavior in the workplace, where there may be several storeys and hence extensive opportunity for stair use? Should exposure to interventions have even a modest effect on subsequent stair use, however, the health benefits could be significant. For instance, Eves and Masters recently calculated that an $80 \mathrm{~kg}$ man ascending a typical flight of domestic stairs eight times a day would expend 10,754 Kcals per annum, or the equivalent of nearly four days worth of food. $^{41}$

To summarise, it appears that in public-access settings stair climbing interventions require a message component. Indeed, when the current message was introduced the effects at the target staircase were the greatest hitherto reported. Exposure to the message also produced a significant and sustained increase in descending stair use. This effect provides evidence that the impact of message prompts on pedestrian behavior generalizes to subsequent point-of-choice situations. Taken together, our findings emphasise the potential of promoting stair use as a means of elevating population activity levels. The challenge now is to determine optimal message 
characteristics and demonstrate generalization effects in terms of the more energy intensive behavior of stair climbing.

\section{SO WHAT?}

Previous interventions aimed at increasing stair use in the workplace have reported positive effects of environmental changes, such as redecorating and installing artwork. However, this study suggests that in public venues, such as shopping malls, campaigns should include a written message in order to change behavior. Furthermore, our results indicate that message prompts continue to influence pedestrians' stair/escalator choices beyond initial exposure to the intervention. As such, stair climbing campaigns may engage the public in more physical activity than previously realised. Taken together, our findings emphasize the efficacy of promoting stair use as an inexpensive means of increasing population activity levels. 


\section{References}

1. Booth FW, Gordon SE, Carlson CJ, Hamilton M.T. Waging war on modern chronic diseases: primary prevention through exercise biology. J Appl Physiol. 2000;88:774-787.

2. Physical Activity and Health: A Report of the Surgeon General. Atlanta, GA: National Centre for Chronic Disease Prevention and Health Promotion. Centers for Disease Control and Prevention; 1996.

3. Healthy People 2000 Final Review. Hyattsville, Maryland: National Centre for Health Statistics. Public Health Service; 2001.

4. Health Survey for England 1998. London: Office for National Statistics. The Stationary Office; 2004

5. Dunn AL, Andersen RE, Jakicic JM. Lifestyle physical activity interventions: History, short- and long-term effects, and recommendations. Am J Prev Med. 1998;15:398-412.1.

6. Department of Health and Human Services, Centres for Disease Control and Prevention. StairWELL to Better Health: A Worksite Intervention. Available at: http://www.cdc.gov/nccdphp/dnpa/stairwell/index.htm. Accessed October 13, 2004.

7. Edwards P. Stair walking...a few steps to better health. Can J Public Health. 1983;74:6365.

8. Bassett DR, Vachon JA, Kirkland AO, Howley ET, Duncan GE, Johnston KR. Energy cost of stair climbing and descending on the college alumnus questionnaire. Med Sci Sports Exerc. 1997;29:1250-1254. 
9. Teh KC, Aziz AR. Heart rate, oxygen uptake, and energy cost of ascending and descending the stairs. Med Sci Sports Exerc. 2002;34:695-699.

10. Boreham CAG, Kennedy RA, Murphy MH, Tully M, Wallace WFM, Young I. Training effects of short bouts of stair climbing on cardiorespiratory fitness, blood lipids, and homocysteine in sedentary young women. Br J Sports Med. 2005;39:590-593.

11. Ilmarinen J, Ilmarinen R, Koskela A. Training effects of stair-climbing during office hours on female employees. Ergonomics. 1979;22:507-516.

12. Eves FF, Webb OJ. Worksite interventions to increase stair climbing; Reasons for caution. Prev Med. In press.

13. Kerr J, Eves FF, Carroll D. Six-month observational study of prompted stair climbing. Prev Med. 2001;33:422-427.

14. Aarts H, Dijksterhuis AP. The automatic activation of goal-directed behaviour: The case of travel habit. J Environ Psychol. 2000;20:75-82.

15. Aarts H, Paulussen T, Schaalma H. Physical exercise habit: on the conceptualization and formation of habitual health behaviours. Health Educ Res. 1997;12:363-374.

16. Aarts H, Verplanken B, van Knippenberg A. Habit and information use in travel mode choices. Acta Psychol. 1997;96:1-14.

17. Oulette JA, Wood W. Habit and intention in everyday life: The multiple processes by which past behavior predicts future behavior. Psychol Bull. 1998;124:54-74. 
18. Wood W, Tam L, Witt MG. Changing circumstances, disrupting habits. J Pers Soc Psychol. 2005;88:918-933.

19. Andersen RE, Franckowiak SC, Snyder J, Bartlett SJ, Fontaine KR. Can inexpensive signs encourage the use of stairs? Results from a community intervention. Ann Intern Med. 1998;129:363-369.

20. Blamey A, Mutrie N, Aitchison T. Health promotion by encouraged use of stairs. $\mathrm{Br}$ Med J. 1995;311:289-290.

21. Brownell KD, Stunkard AJ, Albaum JM. Evaluation and modification of exercise patterns in the natural environment. Am J Psychiatry. 1980;137:1540-1545.

22. Coleman KJ, Gonzalez EC. Promoting stair use in a US-Mexico border community. Am J Public Health. 2001;91:2007-2009.

23. Kerr J, Eves FF, Carroll D. Posters can prompt less active people to use the stairs. $J$ Epidemiol Community Health. 2001;54:942-943.

24. Kerr J, Eves FF, Carroll D. The influence of poster prompts on stair use: the effects of setting, poster size and content. Br J Health Psychol. 2001;6:397-405.

25. Mutrie N, Blamey A, Aitchison T. Why do fewer women choose stairs? J Sport Sci. 1996;14:16-17.

26. Russell WD, Hutchison J. Comparison of health promotion and deterrent prompts in increasing use if stairs over escalators. Percept Mot Skills. 2000;91:55-61. 
27. Kerr J, Eves FF, Carroll D. Getting more people on the stairs: the impact of a new message format. J Health Psychol. 2001;6:495-500.

28. Kerr J, Eves FF, Carroll D. Encouraging stair use: stair-riser banners are better than posters. Am J Public Health. 2001;91:1192-1193.

29. Webb OJ, Eves FF. Promoting stair use: single versus multiple stair-riser messages. Am J Public Health. 2005;95:1543-1544.

30. Boutelle KN, Jeffery RW, Murray DM, Schmitz KH. The use of signs, artwork, and music to promote daily lifestyle activity in a public building. Am J Public Health. 2001;91:20042006.

31. Kerr NA, Yore MM, Ham SA, Dietz WH. Increasing stair use in a worksite through environmental changes. Am J Health Promot. 2004;18:312-315.

32. Yu S, Yarnell JWG, Sweetnam PM, Murray L. What level of physical activity protects against premature cardiovascular death? The Caerphilly study. Heart. 2003;89:502-506.

33. Webb OJ, Eves FF. Promoting stair climbing: Effects of message specificity and validation. Health Educ Res. In press.

34. Eves FF, Webb OJ, Mutrie N. A workplace intervention to promote stair climbing: greater effects in the overweight. Obesity. In press.

35. Coupland CA, Cliffe S J, Bassey E J, Grainge MJ, Hosking DJ, Chilvers, CED. Habitual physical activity and bone mineral density in postmenopausal women in England. Int $J$ Epidemiol. 1999;28:241-246. 
36. Loy SF, Conley LM, Sacco ER, Vincent WJ, Holland GJ, Sletten EG, Trueblood PR. Effects of stairclimbing on VO2max and quadriceps strength in middle-aged females. Med Sci Sports Exerc. 1994;26:241-247.

37. Gärling T, Gärling E. Distance minimization in downtown pedestrian shopping. Environ Plan A. 1988;20:547-554.

38. Hughes RL. A continuun theory for the flow of pedestrains. Transp Res B. 2002;36:507535.

39. Anonymous. Uphill or downhill: The health benefits depend on where you're headed. Harv Womens Health Watch. 2005;7:3.

40. Verplanken B, Aarts H, van Knippenberg A. Habit, information acquisition, and the process of making travel mode choices. Eur J Soc Psychol. 1997;27:539-560.

41. Eves FF, Masters RSW. An uphill struggle: Effects of a point-of-choice stair climbing intervention in a non-English speaking population. Int J Epidemiol. 2006;35:1286-1290. 